\title{
Predicting light-induced stomatal movements based on the redox state of plastoquinone: theory and validation
}

\author{
Johannes Kromdijk ${ }^{1,2} \cdot K_{\text {Katarzyna Głowacka }}^{1,3,5} \cdot$ Stephen P. Long ${ }^{1,4}$
}

Received: 14 June 2018 / Accepted: 25 February 2019 / Published online: 19 March 2019

(c) The Author(s) 2019

\begin{abstract}
Prediction of stomatal conductance is a key element to relate and scale up leaf-level gas exchange processes to canopy, ecosystem and land surface models. The empirical models that are typically employed for this purpose are simple and elegant formulations which relate stomatal conductance on a leaf area basis to the net rate of $\mathrm{CO}_{2}$ assimilation, humidity and $\mathrm{CO}_{2}$ concentration. Although light intensity is not directly modelled as a stomatal opening cue, it is well-known that stomata respond strongly to light. One response mode depends specifically on the blue-light part of the light spectrum, whereas the quantitative or 'red' light response is less spectrally defined and relies more on the quantity of incident light. Here, we present a modification of an empirical stomatal conductance model which explicitly accounts for the stomatal red-light response, based on a mesophyll-derived signal putatively initiated by the chloroplastic plastoquinone redox state. The modified model showed similar prediction accuracy compared to models using a relationship between stomatal conductance and net assimilation rate. However, fitted parameter values with the modified model varied much less across different measurement conditions, lessening the need for frequent re-parameterization to different conditions required of the current model. We also present a simple and easy to parameterize extension to the widely used Farquhar-Von Caemmerer-Berry photosynthesis model to facilitate coupling with the modified stomatal conductance model, which should enable use of the new stomatal conductance model to simulate ecosystem water vapour exchange in terrestrial biosphere models.
\end{abstract}

Keywords Stomatal conductance model $\cdot$ Light response $\cdot$ Plastoquinone $\cdot$ Chlorophyll fluorescence $\cdot$ Gas exchange $\cdot$ Crop models

Electronic supplementary material The online version of this article (https://doi.org/10.1007/s11120-019-00632-x) contains supplementary material, which is available to authorized users.

Johannes Kromdijk

jk417@cam.ac.uk

1 Carl R. Woese Institute for Genomic Biology, University of Illinois at Urbana-Champaign, 1206 West Gregory Drive, Urbana, IL 61801, USA

2 Department of Plant Sciences, University of Cambridge, Downing Site, Cambridge CB23EA, UK

3 Institute of Plant Genetics, Polish Academy of Sciences, 60-479 Poznan, Poland

4 Lancaster Environment Centre, University of Lancaster, Bailrigg LA1 1YX, UK

5 Present Address: Department of Biochemistry, University of Nebraska-Lincoln, N246 Beadle Center, 1901 Vine Street, Lincoln, NE, USA

\section{Introduction}

Terrestrial plants need to take up water from the surrounding environment, retain or transfer water internally, as well as acquire carbon dioxide from the surrounding air to drive photosynthetic carbon assimilation. This trade-off between optimizing carbon uptake via atmospheric diffusion versus minimizing water loss to the atmosphere drove the evolution of highly specialized, controllable stomatal pores in the epidermis of plant leaves (Chater et al. 2017). Stomatal pores are flanked by a pair of guard cells, the only photosynthetic cells of the epidermis, in which turgor changes regulate the pore's aperture in response to a variety of cues (Kollist et al. 2014), such as leaf (and plant) water status (Mott and Parkhurst 1991; Whitehead 1998), carbon dioxide concentration (Engineer et al. 2016) and light (Assman and Shimazaki 1999; Kaiser and Kappen 1997). The importance of the control of stomatal aperture for plant fitness is clear. Stomatal conductance to water vapour strongly determines 
transpiratory water loss at leaf-level (Pearcy et al. 1989) and this relationship can be scaled to canopy transpiration, when accounting for leaf area, canopy conductance and degree of coupling between the canopy and atmosphere (e.g. Mielke et al. 1999). In doing so, it can be shown that stomatal movements significantly influence ecosystem water (and energy) exchange (Wehr et al. 2017). In fact, recent estimates show that transpiratory water loss through stomata accounts for $43-75 \%$ of global terrestrial evapotranspiration (Wei et al. 2017). This importance of stomatal conductance as a control factor for gaseous fluxes across spatial scales emphasizes the need for robust stomatal conductance models to accurately simulate changes in response to-and interactions withthe surrounding environment in current and future climate scenarios.

A wide variety of models for stomatal conductance exist, ranging from very detailed to more simplified descriptions (for reviews, see Buckley 2017; Damour et al. 2010). The majority of stomatal conductance models cover only steady state responses, although significant progress is being made to capture dynamic behaviour of stomatal conductance (Bellasio et al. 2017; Vialet-Chabrand et al. 2017; Wang et al. 2017). Despite these advances, the empirical Ball-Woodrow-Berry (BWB) model (Ball et al. 1986) is still the most widely used prediction tool for stomatal conductance in models extending across spatial scales. The BWB model is a very simple, elegant formulation, which relates (steady state) stomatal conductance to the humidity and $\mathrm{CO}_{2}$ concentration of air surrounding the leaf, and the prevailing rate of photosynthesis, using slope $\left(g_{1}\right)$ and intercept $\left(g_{0}\right)$ parameters. The simplicity of the BWB model facilitates easy coupling to the Farquhar-Von Caemmerer-Berry (FvCB) photosynthesis model (Farquhar et al. 1980), which has been convenient for use in leaf and canopy gas exchange models, as well as ecosystem and land surface models for climate simulation (Bonan et al. 2014).

The original BWB model considers humidity as a percentage of saturated vapour pressure, but this has been altered in several modified versions to a parameter based on vapour pressure deficit (e.g. Dougherty et al. 1994; Leuning 1995; Medlyn et al. 2011). Additional dependencies on soil moisture, plant water status and abscisic acid concentration (Tenhunen et al. 1990; Wang and Leuning 1998; Gutschick and Simonneau 2002) can also be added. The effects of $\mathrm{CO}_{2}$ on stomatal movements are directly accounted for via multiplication with the inverse of ambient $\mathrm{CO}_{2}$ concentration, as well as via an implicit feedback through multiplication with net $\mathrm{CO}_{2}$ assimilation rate $\left(A_{n}\right)$, which is itself responsive to $\mathrm{CO}_{2}$ concentration. The influence of light on stomatal movements is not explicitly accounted for in the BWB model, but is implicitly assumed to be equal to the effects of light on $A_{n}$, thus assuming a direct link between photosynthesis and light-induced stomatal movements. Whereas this assumption is a convenient approximation, it is not consistent with current understanding of light-induced stomatal movements. Instead, light affects stomatal movements in at least two separate ways. Firstly, illumination with (low intensity) blue light activates phototropins, blue-light photoreceptors, which in turn activate a signal transduction chain leading to stomatal opening (Inoue and Kinoshita 2017). These bluelight effects can be most clearly observed in the background of red-light illumination, which also stimulates stomatal opening. However, whereas several signalling components of the blue-light response of stomatal opening have been elucidated, the 'quantitative' or 'red light' response of stomatal conductance is less well understood. Some evidence suggests that phytochromes A and B, red:far-red light photoreceptors, might be involved (Wang et al. 2010) as well as a specific set of MYB transcription factors (AtMYB60 and AtMYB61, Liang et al. 2005). Additionally, whereas the blue-light response appears entirely located in the guard cells, the red-light response seems to depend on a mesophyll-derived signal (Mott et al. 2008; Lawson et al. 2014). This signal was long assumed to be directly related to photosynthesis, but stomatal conductance in plants with transgenically decreased photosynthetic capacity was not decreased proportionally (e.g. Von Caemmerer et al. 2004; Baroli et al. 2008; Lawson et al. 2008), providing evidence that the mesophyll signal does not scale directly with photosynthetic rates. Additionally, responses to red light cannot simply be explained by concomitant effects on intercellular $\mathrm{CO}_{2}$ concentration $\left(C_{\mathrm{i}}\right)$, since stomata still respond to red light when $C_{\mathrm{i}}$ is kept constant (Messinger et al. 2006). Busch (2014) suggested that instead of a photosynthesis-derived signal, the redox state of the chloroplastic plastoquinone (PQ) pool might be signalled to the stomatal guard cells. Consistent with this hypothesis, we recently observed tightly and linearly coordinated changes in the redox state of quinone A, estimated by fluorescence parameter $1-q_{\mathrm{L}}$ (Kramer et al. 2004) and stomatal conductance in tobacco with modified levels of photosystem II subunit S (PsbS) (Głowacka et al. 2018), which is a strong determinant of the amplitude of non-photochemical quenching and therefore also affects the redox state of the chloroplastic electron transport chain.

In the current manuscript we present a modified stomatal conductance model, which explicitly accounts for these observed responses. The parameterization of the resulting model is demonstrated to be less sensitive to measurement conditions compared to the BWB models which simulate stomatal conductance as a function of net assimilation rate. We also show that a simple extension to the FvCB photosynthesis model can be used to predict $1-q_{\mathrm{L}}$ from combined gas exchange and chlorophyll fluorescence measurements, which facilitates coupling to the modified stomatal conductance model. 


\section{Materials and methods}

\section{Modified stomatal conductance model}

The BWB model (Ball et al. 1986) calculates stomatal conductance to water vapour from a linear product of net assimilation rate $A_{n}$, relative humidity $h_{\mathrm{s}}$ and the inverse of $\mathrm{CO}_{2}$ concentration surrounding the leaf $\left(C_{\mathrm{a}}\right)$. Here we use the recent version by Medlyn et al. (2011) as a starting point, where the inverse square-root of atmospheric vapour pressure deficit $\left(\mathrm{VPD}_{\mathrm{A}}\right)$ is used instead of $h_{\mathrm{s}}$ to capture effects of humidity on $g_{\mathrm{s}}$. The resulting term is scaled empirically to measured stomatal conductance, using a slope parameter $g_{1}$ and intercept parameter $g_{0}$, such as shown in Eq. (1).

$g_{\mathrm{s}}=g_{0}+1.6 \times\left(1+\frac{g_{1}}{\sqrt{\mathrm{VPD}_{\mathrm{A}}}}\right) \times \frac{A_{n}}{C_{\mathrm{a}}}$

Recent data (Głowacka et al. 2018) suggest that the stomatal 'quantitative' or 'red' light response may be initiated by a PQ redox signal, which we approximate by $1-q_{\mathrm{L}}$ i.e. the redox state of the quinone bound to the $Q_{\mathrm{A}}$ site at photosystem II (PSII). We therefore replaced $A_{n}$ in Eq. (1) with $\left(1-q_{\mathrm{L}}\right)$ (Eq. 2). Note that the empirical constants in Eq. (1) are used similarly to Eq. (2) but have been renamed, to facilitate easy comparison between parameter estimation based on the Medlyn model and the modified model.

$g_{\mathrm{s}}=g_{0, \text { new }}+1.6 \times\left(1+\frac{g_{1, \text { new }}}{\sqrt{\mathrm{VPD}_{\mathrm{A}}}}\right) \times \frac{1-q_{\mathrm{L}}}{C_{\mathrm{a}}}$

\section{Extension of the FvCB photosynthesis model to simulate $q_{\mathrm{L}}$}

The biochemical model for leaf photosynthesis by Farquhar et al. (1980; abbreviated as FvCB model) is widely used in conjunction with stomatal models such as Eq. (1). Coupling between the FvCB model and the new stomatal conductance model in Eq. (2) would require simulation of $q_{\mathrm{L}}$. Therefore, we present a simple extension of the FvCB model to allow simulation of $q_{\mathrm{L}}$. The FvCB model has a switch-point structure and simulates net assimilation rate as the minimum of three limiting factors: RuBP carboxylation-limited rate $\left(A_{\mathrm{c}}\right)$, RuBP regeneration-limited rate $\left(A_{\mathrm{j}}\right)$ and triose phosphate utilization limited rate $\left(A_{\mathrm{TPU}}\right)$.

$$
\begin{aligned}
& A_{\mathrm{c}}=\frac{V_{\mathrm{cmax}} \times\left(C_{\mathrm{c}}-\Gamma^{*}\right)}{C_{\mathrm{c}}+K_{\mathrm{c}} \times\left(1+\frac{O_{\mathrm{c}}}{K_{\mathrm{o}}}\right)}-R_{\mathrm{d}} \\
& A_{\mathrm{j}}=\frac{J \times\left(C_{\mathrm{c}}-\Gamma^{*}\right)}{4 C_{\mathrm{c}}+8 \Gamma^{*}}-R_{\mathrm{d}}
\end{aligned}
$$

$A_{\mathrm{TPU}}=3 V_{\mathrm{TPU}}-R_{\mathrm{d}}$

$A_{\mathrm{n}}=\min \left(A_{\mathrm{c}}, A_{\mathrm{j}}, A_{\mathrm{TPU}}\right)$

here $V_{\text {cmax }}$ is the maximal rate of RuBP carboxylation and $K_{\mathrm{c}}$ and $K_{\mathrm{o}}$ are the Michaelis-Menten constants to describe $\mathrm{CO}_{2}$ and $\mathrm{O}_{2}$ effects on RuBP carboxylation. $C_{\mathrm{c}}$ represents the chloroplastic $\mathrm{CO}_{2}$ concentration, $\Gamma^{*}$ represents the $\mathrm{CO}_{2}$ compensation point in the absence of $R_{\mathrm{d}}$ and $R_{\mathrm{d}}$ represents mitochondrial respiration not associated with photorespiration. $V_{\mathrm{TPU}}$ is the maximal rate of triose phosphate utilization and $O_{c}$ represents the $\mathrm{O}_{2}$ concentration in the chloroplast, which was assumed to equal ambient.

Next, the rate of whole-chain electron transport $(J$; Eq. 4) was modelled as a function of absorbed light intensity $\left(\mathrm{PFD}_{\mathrm{abs}}\right)$ using a non-rectangular hyperbola, with initial slope $\alpha$, asymptote $J_{\max }$ and shape factor $\theta$.

$J=\frac{\alpha \times f_{\mathrm{PSII}} \times \mathrm{PFD}_{\mathrm{abs}}+J_{\text {max }}-\sqrt{\left(\alpha \times f_{\mathrm{PSII}} \times \mathrm{PFD}_{\mathrm{abs}}\right)^{2}-4 \times \theta \times \alpha \times f_{\mathrm{PSII}} \times \mathrm{PFD}_{\mathrm{abs}}+J_{\text {max }}}}{2 \times \theta}$

here $f_{\mathrm{PSII}}$ represents the proportion of absorbed light partitioned to PSII. The level of $J$ was used to calculate the operating efficiency of photosystem II $\left(\Phi_{\text {PSII }}\right)$ at a given light level:

$\Phi_{\mathrm{PSII}}=\frac{J}{\mathrm{PFD}_{\mathrm{abs}} \times f_{\mathrm{PSII}}}$

To describe the steady state level of non-photochemical quenching (NPQ) as a function of light intensity (PFD), a sigmoidal Hill function was used (Eq. 6a), with basal level $\mathrm{NPQ}_{0}$, light intensity at half amplitude $\left(K_{\mathrm{NPQ}}\right)$, Hill coefficient $(n \mathrm{NPQ})$ and asymptote $\left(\mathrm{NPQ}_{\max }\right)$. The level of NPQ at the $\mathrm{PFD}=0$ limit was assumed to equal zero (Eq. 6b).

$\mathrm{PFD}>0 \rightarrow \mathrm{NPQ}=\frac{\mathrm{NPQ}_{\max }-\mathrm{NPQ}_{0}}{\left[\left(\frac{K_{\mathrm{NPQ}}}{\mathrm{PFD}_{\mathrm{abs}}}\right)^{n \mathrm{NPQ}}+1\right]}+\mathrm{NPQ}_{0}$

$\mathrm{PFD}=0 \rightarrow \mathrm{NPQ}=0$

Maximal fluorescence without dark-adaptation at a given light level $\left(F_{\mathrm{m}}^{\prime}\right)$ was calculated using NPQ (from Eqs. 6a, $6 b)$ and dark-adapted maximal fluorescence $F_{m}$ according to Eq. (7). The corresponding level of $F^{\prime}$ was computed with Eq. (8), using $\Phi_{\text {PSII }}$ from Eq. (5):

$F_{\mathrm{m}}^{\prime}=\frac{F_{\mathrm{m}}}{\mathrm{NPQ}+1}$

$F^{\prime}=\frac{F_{\mathrm{m}}^{\prime}}{1-\Phi_{\mathrm{PSII}}}$ 
To predict minimal fluorescence without dark-adaptation $\left(F_{\mathrm{o}}^{\prime}\right)$ as a function of light intensity, we separately considered effects of suppression of fluorescence via $N P Q$ and elevation of fluorescence due to photo-inactivated reaction centres. The decrease in $F_{\mathrm{o}}^{\prime}$ relative to $F_{\mathrm{o}}$ as a result of $N P Q$ (calculated as $F_{\mathrm{oNPQ}}^{\prime}$ ) was estimated from $F_{\mathrm{m}}^{\prime}$ and $F_{\mathrm{o}}$ according to Oxborough and Baker (1997):

$F_{\mathrm{oNPQ}}^{\prime}=\frac{F_{\mathrm{o}}}{\frac{F_{\mathrm{v}}}{F_{\mathrm{m}}}+\frac{F_{\mathrm{o}}}{F_{\mathrm{m}}^{\prime}}}$

Using $F_{\mathrm{oNPQ}}^{\prime}$ from Eq. (9), the effects of $N P Q$ on the maximal PSII quantum efficiency in the light $\left(F_{\mathrm{v}}^{\prime} / F_{\mathrm{m}}^{\prime}\right)$ can be predicted:

$\left(\frac{F_{\mathrm{v}}^{\prime}}{F_{\mathrm{m}}^{\prime}}\right)_{\mathrm{NPQ}}=1-\frac{F_{\mathrm{oNPQ}}^{\prime}}{F_{\mathrm{m}}^{\prime}}$

Next, we used an empirical relationship to predict the elevation of minimal fluorescence due to inactivation of reaction centres. Hendrickson et al. (2005) showed that the energy flux approximated by $0.5 \times \mathrm{PFD}_{\mathrm{abs}} \times \frac{F^{\prime}}{F_{\mathrm{m}}^{\prime}}$ is a reasonable estimator of the rate constant of photo-inactivation. Therefore, we predicted the relative difference between $\left(F_{\mathrm{v}}^{\prime} / F_{\mathrm{m}}^{\prime}\right)_{\mathrm{NPQ}}$ from Eq. (10) and observed $F_{\mathrm{v}}^{\prime} / F_{\mathrm{m}}^{\prime}$ by a linear function of $0.5 \times \mathrm{PFD}_{\mathrm{abs}} \times F^{\prime} / F_{\mathrm{m}}^{\prime}$ according to Eq. (11):

$1-\frac{\left(\frac{F_{\mathrm{v}}^{\prime}}{F_{\mathrm{m}}^{\prime}}\right)}{\left(\frac{F_{\mathrm{v}}^{\prime}}{F_{\mathrm{m}}^{\prime}}\right)_{\mathrm{NPQ}}}=m \times\left(0.5 \times \mathrm{PFD}_{\mathrm{abs}} \times \frac{F^{\prime}}{F_{\mathrm{m}}^{\prime}}\right)+n$

The empirical coefficients $m$ and $n$ were fitted on light response curves of chlorophyll fluorescence parameters. Combining Eq. (11) with simulated fluorescence levels from Eqs. (7) and (8) then allowed calculation of $q_{\mathrm{L}}$ using the formulation by Kramer et al. (2004):

$q_{\mathrm{L}}=\frac{F_{\mathrm{m}}^{\prime}-F^{\prime}}{F_{\mathrm{m}}-F_{\mathrm{o}}} \times \frac{F_{\mathrm{o}}^{\prime}}{F^{\prime}}$

\section{Coupling the photosynthesis and stomatal conductance models}

Using the equations presented above, $q_{\mathrm{L}}$ can be calculated, which provides a handle for coupling the photosynthesis model with the modified stomatal conductance model. First of all, the intercellular $\mathrm{CO}_{2}$ concentration $C_{\mathrm{i}}$ is dependent on the $\mathrm{CO}_{2}$ concentration in the chloroplast $C_{\mathrm{c}}$ at a given rate of photosynthesis. The value of $C_{\mathrm{i}}$ could therefore be modelled based on the photosynthesis model using Fick's law of diffusion (Eq. 13).
$C_{\mathrm{i}}=C_{\mathrm{c}}+\frac{A_{\mathrm{n}}}{g_{\mathrm{m}} \times P}$

here $P$ represents atmospheric pressure and $g_{\mathrm{m}}$ is mesophyll conductance to $\mathrm{CO}_{2}$. Additionally, $C_{\mathrm{i}}$ can be predicted from the $\mathrm{CO}_{2}$ concentration surrounding the leaf $\left(C_{\mathrm{a}}\right)$, the rate of $A_{n}$, and the value of stomatal conductance $\left(g_{\mathrm{s}}\right)$ from Eqs. (1) or (2).

$C_{\mathrm{i}}=\frac{\left[\frac{1}{\frac{1.6}{g_{\mathrm{s}}}+\frac{1.37}{g_{\mathrm{bl}}}}-\frac{\mathrm{VPD}_{\mathrm{L}}}{2 \times P \times\left(\frac{1}{g_{\mathrm{s}}}+\frac{1}{g_{\mathrm{bl}}}\right)}\right] \times C_{\mathrm{a}}-A_{n}}{\left[\frac{1}{\frac{1.6}{g_{\mathrm{s}}}+\frac{1.37}{g_{\mathrm{bl}}}}+\frac{\mathrm{VPD}_{\mathrm{L}}}{2 \times P \times\left(\frac{1}{g_{\mathrm{s}}}+\frac{1}{g_{\mathrm{bl}}}\right)}\right]}$

here $g_{b 1}$ represents the conductance to $\mathrm{H}_{2} \mathrm{O}$ through the leaf boundary layer, $\mathrm{VPD}_{\mathrm{L}}$ represents leaf-to-air vapour pressure deficit. Using these two formulations for $C_{\mathrm{i}}$, the models were coupled by iterative minimization of differences between Eqs. (13) and (14).

\section{Parameter estimation for the Medlyn model and modified stomatal conductance model}

The parameters for the stomatal conductance models were estimated using measurements on tobacco plants. Tobacco seeds (Nicotiana tabacum, cv 'Petite Havana') were germinated on soilless cultivation medium (LC1 Sunshine mix, Sun Gro Horticulture, Agawam, MA, USA) in a controlled environment walk-in growing chamber (Environmental Growth Chambers, Chagrin Falls, OH, USA) with photoperiod set to $12 \mathrm{~h}$ and temperature controlled at $25 / 23^{\circ} \mathrm{C}$ (day/ night). Five days after germination seedlings were moved to the greenhouse, transplanted to $9 \times 4$ potting trays $(3600$ series, Hummert International, Earth City, MO, USA) and grown until two true leaves had emerged. When two true leaves had emerged, seedlings were transplanted to $3.8 \mathrm{~L}$ pots (400C, Hummert International, Earth City, MO, USA) filled with growing medium (LC1 Sunshine mix, Sun Gro Horticulture) supplemented with $10 \mathrm{~g}$ granulated fertilizer per pot (Osmocote Plus 15/9/12, The Scotts Company LLC, Marysville, $\mathrm{OH}, \mathrm{USA})$. Pots were spaced $30 \mathrm{~cm}$ apart on greenhouse tables and watered and positions randomized every 2 days.

Gas exchange measurements were performed on the youngest fully expanded leaf after 2.5 weeks of growth (leaf 5), using an open gas exchange system (LI6400XT, LI-COR, Lincoln, Nebraska, USA) equipped with a $2 \mathrm{~cm}^{2}$ leaf chamber fluorometer (LCF6400-40, LI-COR), corrected for diffusive leaks between cuvette and the surrounding atmosphere. Two sets of light response curves of photosynthesis, fluorescence and stomatal conductance were used to 
parameterize the Medlyn and modified stomatal conductance models (see Fig. S1). Leaves were dark-adapted and clamped in the gas exchange cuvette, with block temperature controlled at $25{ }^{\circ} \mathrm{C}$. After measuring $F_{\mathrm{o}}$ and $F_{\mathrm{m}}$ chlorophyll fluorescence levels, light intensity was increased stepwise from 0 to $50,80,110,140,170,200,300,400$, $500,600,800,1000,1500$ and $2000 \mu \mathrm{mol} \mathrm{m}{ }^{-2} \mathrm{~s}^{-1}$. When steady state was achieved (typically at least 15 min waiting time per step), gas exchange parameters were logged and $F^{\prime}$ and $F_{\mathrm{m}}^{\prime}$ were determined using the multiphase flash routine (Loriaux et al. 2013). Additionally, $F_{\mathrm{o}}^{\prime}$ was measured by switching the actinic light off briefly while turning on far-red LEDs $\left(\lambda_{\max }=740 \mathrm{~nm}\right)$ to rapidly re-oxidize quinone A. The chlorophyll fluorescence levels at each light intensity were used to compute $q_{\mathrm{L}}$ according to Eq. (12). For the first set of light response curves, $\mathrm{CO}_{2}$ concentration inside the cuvette was controlled at $380 \mu \mathrm{mol} \mathrm{mol}^{-1}$ and the light intensities were achieved solely with red light emitting diodes $\left(\lambda_{\max }=630 \mathrm{~nm}\right)$. This set has been previously published in Głowacka et al. (2018). For set 2, $\mathrm{CO}_{2}$ concentration in the reference air was controlled at $1000 \mu \mathrm{mol} \mathrm{mol}^{-1}$ and light intensities were a sum of $90 \%$ red and $10 \%$ blue $\left(\lambda_{\max }=470 \mathrm{~nm}\right)$ on a photon flux basis. The curves were performed on $n=6$ biological replicates for set 1 and $n=7$ for set 2. These measurements resulted in two sets of $g_{s}, A_{n}$ and $1-q_{\mathrm{L}}$, which were used to estimate parameters $g_{0}$ and $g_{1}$ in Eq. (1) as well as $g_{0, \text { new }}$ and $g_{1 \text {,new }}$ in Eq. (2) via linear regression.

\section{Parameter estimation for the photosynthesis model}

Parameter estimation of the photosynthesis model required measuring the capacity for leaf photosynthetic biochemistry (see Fig. S1). For this purpose, $\mathrm{CO}_{2}$ response curves of photosynthesis were performed on the youngest fully expanded leaf ( $n=6$ biological replicates). Leaves were clamped in the gas exchange cuvette with light intensity set to $2000 \mu \mathrm{mol} \mathrm{m}^{-2} \mathrm{~s}^{-1}$ (10\% blue). $\mathrm{CO}_{2}$ concentration in the airstream was controlled to $400 \mu \mathrm{mol} \mathrm{mol}{ }^{-1}$, and block temperature set to $25^{\circ} \mathrm{C}$. After steady state had been achieved, $\mathrm{CO}_{2}$ was varied from 400 to $300,200,100,75,400,400,500$, $600,700,800,1200,1600$ and $1900 \mu \mathrm{mol} \mathrm{mol}^{-1}$. At each $\mathrm{CO}_{2}$ concentration, gas exchange values were logged, when the coefficient of variation in net leaf $\mathrm{CO}_{2}$ uptake rate $\left(A_{n}\right)$ and intercellular $\mathrm{CO}_{2}$ concentration $\left(C_{\mathrm{i}}\right)$ averaged over $10 \mathrm{~s}$ became less than $1 \%$ (minimum wait time 1 min, maximum wait time $4 \mathrm{~min}$ ). $V_{\text {cmax }}$ and $V_{\mathrm{TPU}}$ were obtained by fitting the photosynthesis model according to Sharkey et al. (2007) and temperature corrections within. Mesophyll conductance $\left(g_{\mathrm{m}}\right)$ was not co-fitted but a value of $0.60 \mathrm{~mol} \mathrm{~m}^{-2} \mathrm{~s}^{-1} \mathrm{bar}^{-1}$ at $25{ }^{\circ} \mathrm{C}$ was derived separately on a parallel set of tobacco plants, using carbon isotope discrimination measurements in parallel with gas exchange from cryogenic trapping and isotope ratio mass spectrometry as described in Kromdijk et al. (2010) and model equations outlined in Evans and Von Caemmerer (2013). $R_{\mathrm{d}}$ was estimated as the $y$ intercept from the linear regression of $A_{n}$ versus $J$ at low light (Yin et al. 2009), where $J$ was obtained from the light response curves as described above. To convert incident to absorbed photon flux in both sets of curves, light absorptance was measured on the same leaf position where gas exchange analysis had also been performed, using an integrating sphere (LI1800, LI-COR) connected to a spectrometer (USB-2000, Ocean Optics Inc, Dunedin, Florida, USA). Incident photon flux was converted to absorbed photon flux ( $\mathrm{PFD}_{\mathrm{abs}}$ ) using the measured absorptance at the actinic wavelengths used.

\section{Using the coupled model to predict field observations of $A_{n}$ and $g_{s}$}

Survey-style measurements on field-grown tobacco were performed on a bright, hot day (July 21, 2015) at the University of Illinois farm in Urbana $\left(40.11^{\circ} \mathrm{N}, 88.21^{\circ} \mathrm{W}\right)$. Early morning measurements had to be delayed until all morning dew of the leaves had evaporated, which occurred around 08:00. Thus, measurements were started at 08:15 and repeated every 90 min until 20:15, just prior to sunset. At each time-point, ambient light intensity was first measured using the external PAR-sensor of the LI6400XT. Subsequently, light intensity in the cuvette was set to equal the ambient intensity (using $90 \%$ red and $10 \%$ blue), block temperature was set to measured air temperature and $\mathrm{CO}_{2}$ concentration in the airstream was set to $400 \mu \mathrm{mol} \mathrm{mol}^{-1}$. Leaves were clamped in the cuvette and gas exchange values were logged as soon as stomatal conductance reached steady rates for $10 \mathrm{~s}$ (based on visual assessment of the stripcharts), which happened typically after 1.5-2 min. Parameter estimation for the photosynthesis model was performed using additional $\mathrm{CO}_{2}$ and light response curves measured on the field-grown plants. The coupled model was used to predict stomatal conductance based on the parameter estimates for $g_{0}, g_{1}, g_{0, \text { new }}$ and $g_{1, \text { new }}$ from the plants grown under controlled conditions, as well as using re-calibrated parameter values from a best fit with observations.

\section{Implementation and model fitting}

The equations were implemented in Matlab (Version 8.1.0.604, R2013a, The Mathworks Inc. Natick, MA, USA). Parameter estimation of the stomatal conductance and photosynthesis models was performed using constrained nonlinear minimization ('fmincon' algorithm with global search) of least squares differences. Linear regressions were performed with SigmaPlot (Version 14.0, SYSTAT Software Inc., San Jose, California, USA). Re-calibration of the stomatal conductance model under field conditions was performed by 
minimizing residuals using a grid-search for $g_{0}, g_{1}, g_{0, \text { new }}$ or $g_{1, \text { new }}$.

\section{Results}

\section{Stomatal conductance model}

The measured light responses of stomatal conductance showed highly significant linear correlations with both $A_{n}$ and $1-q_{\mathrm{L}}(p<0.005$, Fig. 1a, b). The slopes of the regressions were significantly different between the two sets of light response curves (Student's $t$ test, $p<0.05$ ), as could be expected from the well-known suppression effect of high $\mathrm{CO}_{2}$ on stomatal movements. The slope of both stomatal conductance models is essentially a linear multiplication of response factors (i.e. $A_{n} \times C_{\mathrm{a}}^{-1} \times \mathrm{VPD}_{\mathrm{A}}^{-0.5}$ or $\left.\left(1-q_{\mathrm{L}}\right) \times C_{\mathrm{a}}^{-1} \times \mathrm{VPD}_{\mathrm{A}}^{-0.5}\right)$. Therefore, the ratio of the slopes of the regressions of $g_{\mathrm{s}}$ against either $A_{n}$ or $1-q_{\mathrm{L}}$ should equal $\left(C_{\mathrm{a}}^{-1}\right.$ set $1 \times$ $\mathrm{VPD}_{A}^{0.5}$ set 1$) /\left(C_{\mathrm{a}}^{-1}\right.$ set $2 \times \mathrm{VPD}_{A}^{0.5}$ set 2$)$, which was calculated to be 2.27 . The measured slope ratio between the linear regressions in Fig. 1a $\left(A_{n}\right.$ vs. $\left.g_{\mathrm{s}}\right)$ was 4.67 , whereas the regressions in Fig. $1 \mathrm{~b}\left(1-q_{\mathrm{L}}\right.$ vs. $\left.g_{\mathrm{s}}\right)$ showed a slope ratio of 3.06 , which was considerably closer to the predicted value. This suggests that the relationship between $g_{\mathrm{S}}$ and $1-q_{\mathrm{L}}$ is more conserved than between $g_{\mathrm{s}}$ and $A_{n}$ when measurement conditions are varied. This was also confirmed by fitting the model parameters $g_{0}$ and $g_{1}$ (Fig. 2a, c) or $g_{0, \text { new }}$ and $g_{1, \text { new }}$ (Fig. 2b, d) for each individual light response curve. One light response curve in set 2 did not converge to a reasonable estimate for $g_{1}$ in the Medlyn model, and was discarded to avoid confounding the comparison between $A_{n}$ and $1-q_{\mathrm{L}}$. For the remaining 12 light response curves, variation in stomatal conductance was adequately captured by both models. However, whereas the fitted slope parameter $g_{1}$ decreased significantly by $58 \%$ for measurements at $1000 \mu \mathrm{mol} \mathrm{mol}^{-1} \mathrm{CO}_{2}$ and $10 \%$ blue compared to $380 \mu \mathrm{mol} \mathrm{mol}^{-1} \mathrm{CO}_{2}$ and $100 \%$ red light $(1.90 \pm 0.25$ vs. $0.60 \pm 0.15, p=0.001$, Fig. 3a), fitted $g_{1 \text {,new }}$ did not vary significantly ( $103 \pm 8$ vs. $84 \pm 8, p=0.10$, Fig. 3b).

\section{Predicting $q_{\mathrm{L}}$ with the extended photosynthesis model}

To facilitate the integration of $1-q_{\mathrm{L}}$ as a predictor of lightinduced stomatal movements in higher level models, we extended the widely used FvCB biochemical model for leaf photosynthesis (Farquhar et al. 1980) to allow simulation of $q_{\mathrm{L}}$. First, leaf biochemical capacity for RuBP carboxylation $\left(V_{\mathrm{c}_{\max }}\right)$ and triose phosphate utilization $\left(V_{\mathrm{TPU}}\right)$ were estimated based on $\mathrm{CO}_{2}$ response curves (Fig. 4a). Light response curves were used to parameterize descriptive equations for whole-chain electron transport rate $J$ (Fig. 4b) and non-photochemical quenching NPQ (Fig. 4c) and estimate the rate of mitochondrial respiration in the light $\left(R_{\mathrm{d}}\right)$ as the $y$ intercept of the initial linear response of $A_{n}$ to $J$ (Fig. 4d). All parameter estimates are shown in Table 1 in "Appendix". These estimates were then used to simulate fluorescence parameters $F_{\mathrm{m}}^{\prime}, F^{\prime}$, and $F_{\mathrm{o}}^{\prime}$ (Fig. 5a-c). Simulation of $F_{\mathrm{o}}^{\prime}$ showed a slight mismatch compared to the measured values at low light intensity, which is due to the fact that the relationship described in Eq. (11) becomes slightly curvi-linear at low light. However, the overall fit between measured and simulated fluorescence parameters was adequate to accurately reproduce most of the observed variation in $q_{\mathrm{L}}\left(R^{2}=0.984\right)$ and the linear correlation did not differ significantly from $x=y(p>0.05$, Fig. 6a, b).

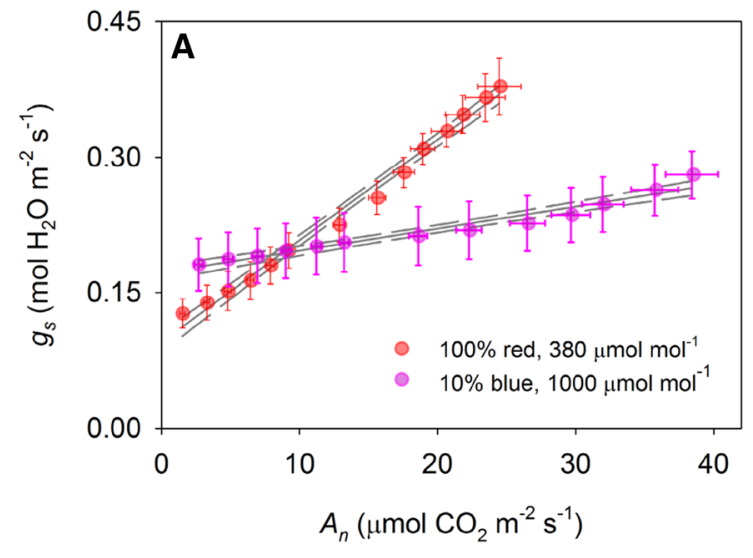

Fig. 1 a Stomatal conductance $\left(g_{\mathrm{s}}\right)$ plotted as a function of net assimilation rate $\left(A_{n}\right)$. b Stomatal conductance plotted as a function of fluorescence parameter $1-q_{\mathrm{L}}$. Red symbols indicate measurements performed at $\mathrm{CO}_{2}$ concentration in the cuvette of $380 \mu \mathrm{mol} \mathrm{mol}{ }^{-1}$,

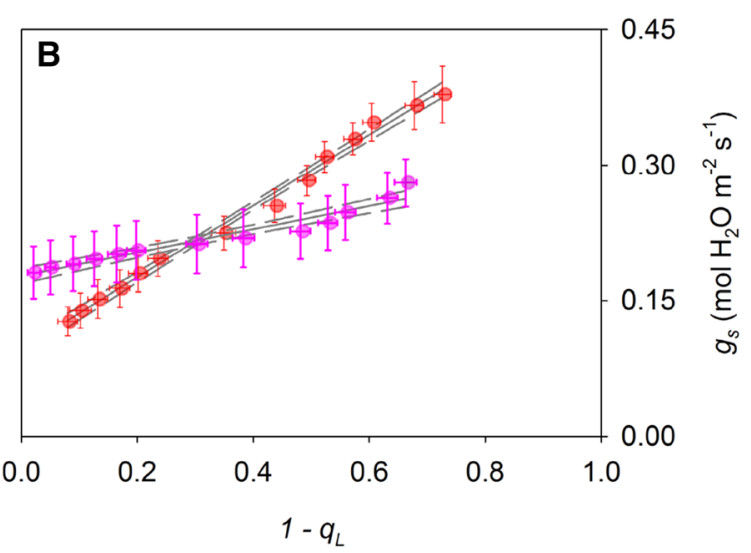

$100 \%$ red light, purple symbols indicate measurements at $\mathrm{CO}_{2}$ of $1000 \mu \mathrm{mol} \mathrm{mol}^{-1}, 90 \%$ red $10 \%$ and blue light. Solid and dashed lines show linear regressions and 95\% confidence intervals, respectively. Error bars indicate standard errors $(n=6-7$ biological replicates $)$ 


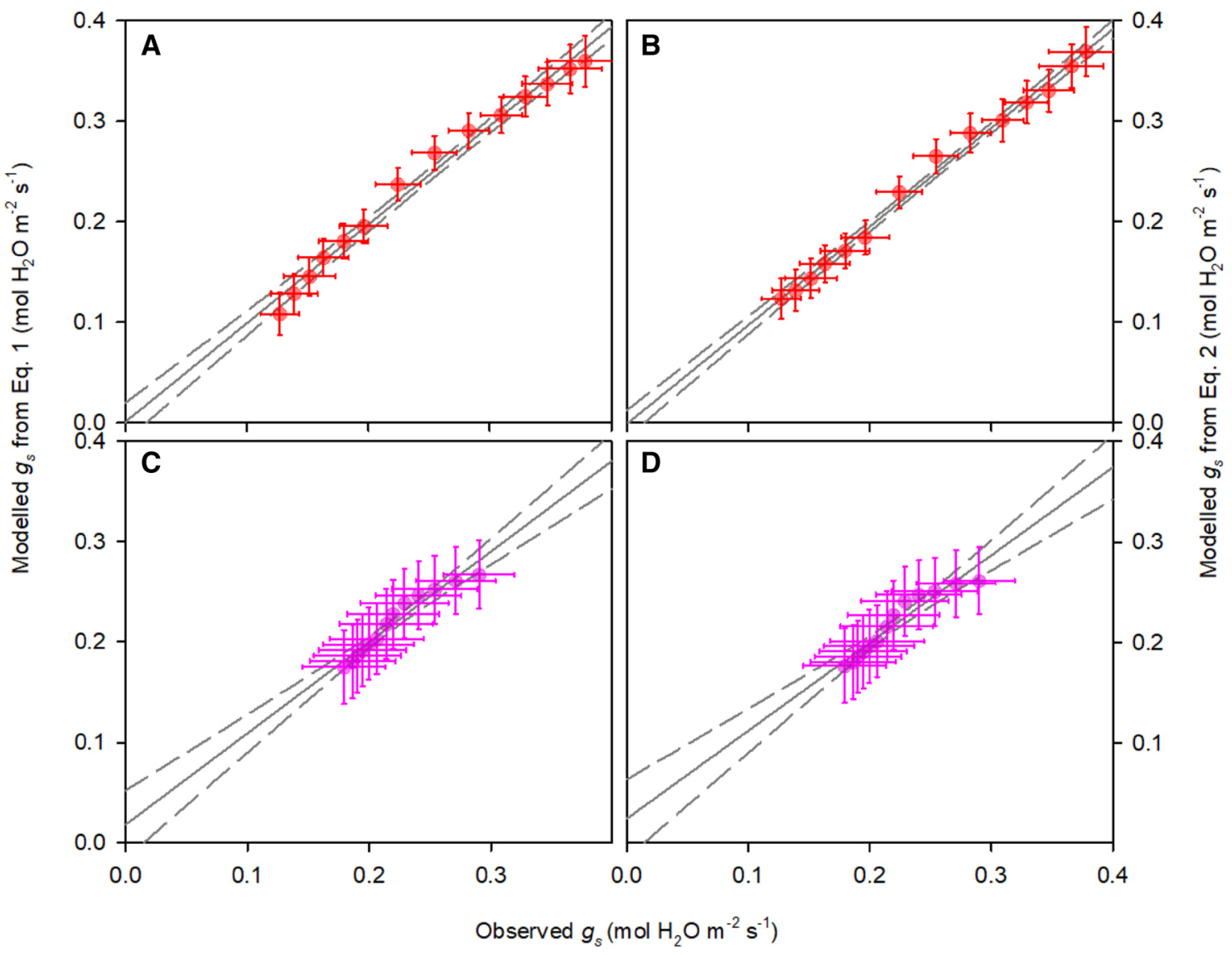

Fig. 2 Measured versus modelled stomatal conductance $\left(g_{\mathrm{s}}\right)$. Stomatal conductance was modelled for measurements performed at $\mathrm{CO}_{2}$ concentration in the cuvette of $380 \mu \mathrm{mol} \mathrm{mol}^{-1}$ and $100 \%$ red light with Eq. (1) (Medlyn et al. 2011, panel a) and with the modified model (Eq. 2, panel b) and for measurements using 90\% red and

\section{Coupled model for photosynthesis and stomatal conductance}

Simulation of $q_{\mathrm{L}}$ through the extended photosynthesis model shown in Fig. 6 provided a coupling point for the modified stomatal conductance model. The coupled stomatal conductance-photosynthesis model was used to simulate $A_{n}$ (Fig. 7a) and $g_{\mathrm{s}}$ (Fig. 7b) as a function of light intensity by iteratively solving differences between the two equations for intercellular $\mathrm{CO}_{2}$ concentration $C_{\mathrm{i}}$ (Eqs. 13 and 14). Both were simulated reasonably accurately across the light response, although a slight mismatch in the curvature of $g_{\mathrm{s}}$ was observed (Fig. 7b).

As an independent verification, diurnal gas exchange measurements on field-grown tobacco were used to further test the performance of the coupled model. Measurements were performed on a well-watered tobacco crop on a hot, clear day in mid-summer (Fig. 8a). The first measurement point was taken at 08.15 , when light intensity had already reached $700 \mu \mathrm{mol} \mathrm{m}{ }^{-2} \mathrm{~s}^{-1}$ and $A_{n}$ and $g_{\mathrm{s}}$ were already quite
$10 \%$ blue light and $\mathrm{CO}_{2}$ of $1000 \mu \mathrm{mol} \mathrm{mol}{ }^{-1}$ with the Medlyn model (panel c) and with the modified model (panel d). Solid and dashed lines show linear regressions and 95\% confidence intervals, respectively. Error bars indicate standard errors ( $n=6$ biological replicates)

high (averaging $20.0 \mu \mathrm{mol} \mathrm{m} \mathrm{m}^{-2} \mathrm{~s}^{-1}$ and $0.55 \mathrm{~mol} \mathrm{~m}^{-2} \mathrm{~s}^{-1}$, respectively; Fig. 8b and c). Subsequent measurements showed a slight increase in $g_{\mathrm{s}}$ towards 11.15 followed by a gradual decline throughout the afternoon. $A_{n}$ also increased towards mid-day, reaching maximum values somewhat later than $g_{\mathrm{s}}$, at $12: 45$ and $14: 15$, followed by a gradual decline throughout the remainder of the photoperiod.

To simulate these observations, we used both stomatal conductance models with either the parameter estimation from plants grown under controlled conditions or re-calibrated on the field-grown plants, while the photosynthesis model was parameterized on the field-grown plants at all simulations. Using the parameter estimates from controlled conditions for either the Medlyn or modified stomatal conductance model resulted in severe underestimation of stomatal conductance and net assimilation rate (Fig. 8b, c) as could be expected based on known differences in stomatal acclimation between controlled versus field conditions. A better match between modelled and observed data was obtained by re-calibration of the stomatal conductance model by 
Fig. 3 Estimated model parameters $\left(g_{0}, g_{0, \text { new }}, g_{1}, g_{1, \text { new }}\right)$ for the stomatal conductance model with either $A_{n}$ (panel a and c) or $1-q_{\mathrm{L}}$ (panel $\mathbf{b}$ and $\mathbf{d}$ ) as the estimator for light-induced stomatal movements. Light response curves were measured with either $100 \%$ red light and $380 \mu \mathrm{mol} \mathrm{mol}^{-1} \mathrm{CO}_{2}$ (set 1) or $90 \%$ red and $10 \%$ blue light and $1000 \mu \mathrm{mol} \mathrm{mol}^{-1} \mathrm{CO}_{2}$ (set 2). Asterisk indicates significant difference between parameter estimate for set 1 versus set 2 ( $p=0.001$, Student's $t$ test, $n=6)$

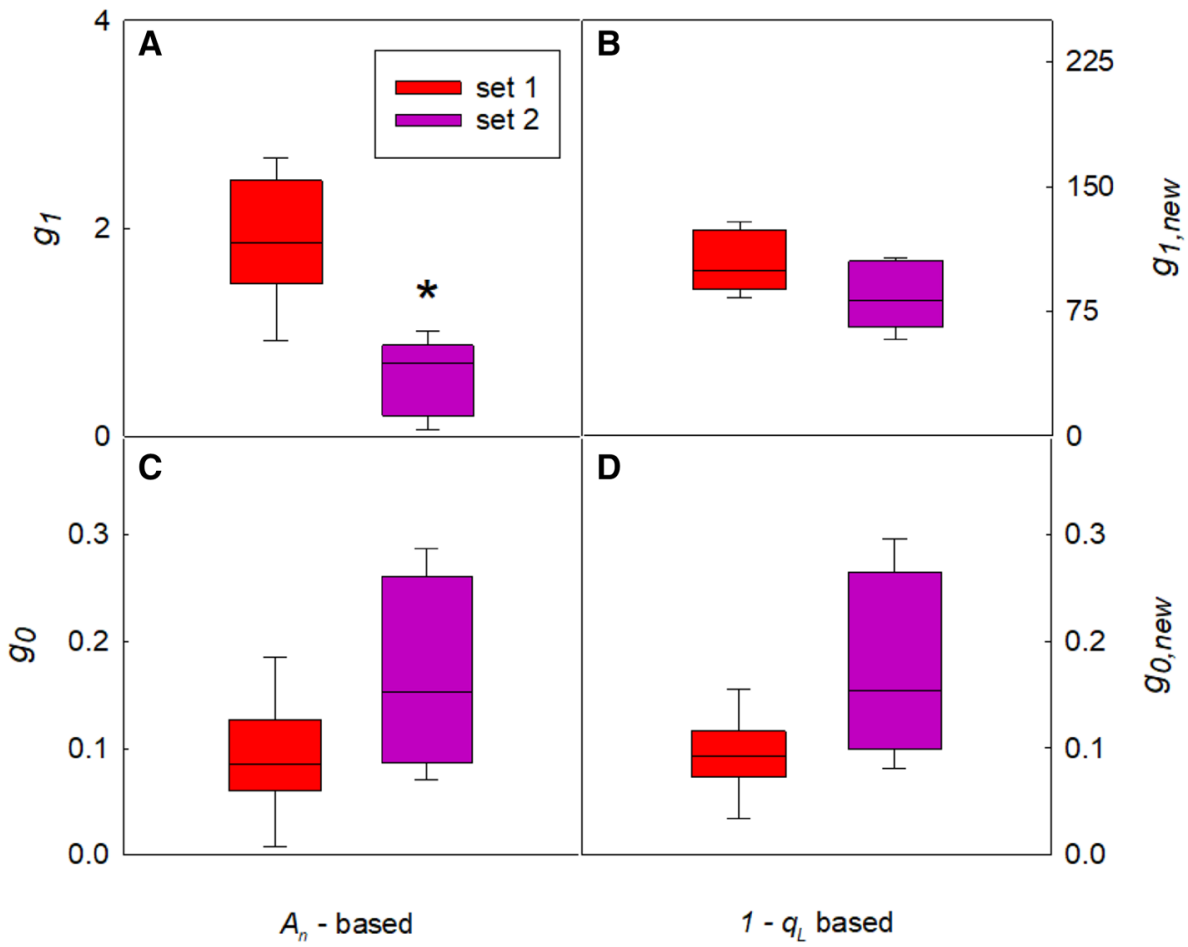

minimizing the residuals between modelled and observed $g_{\mathrm{s}}$. Model predictions with re-calibrated parameters showed a reasonable match with observed $A_{n}$ and $g_{\mathrm{s}}$ for the majority of the time-points except for late in the photoperiod $(17: 15$ and 18:45), where $A_{n}$ and $g_{\mathrm{s}}$ were lower than predicted by the model. The minimized residuals were marginally smaller for the modified model compared to the Medlyn model, $(0.115$ vs. 0.123 ). In addition, the residuals across a wide range of parameter values remained considerably lower in the modified stomatal conductance model, compared to the Medlyn model (0.115-0.162 vs. $0.123-0.210$ for parameter values shown in Fig. S2).

\section{Discussion}

\section{Modelling light-induced stomatal movements}

Models for stomatal conductance are important components of canopy, ecosystem, land surface and even earth system models in predicting future climate and biosphere productivity. Here we have shown that the widely used empirical BWB model for stomatal conductance (version by Medlyn et al. 2011) can be changed to incorporate the putative causal relationship between PQ redox state and light-induced stomatal movements (Busch 2014; Głowacka et al. 2018) yet kept simple enough to facilitate easy integration in models of greater scale. The modification was shown to lead to more conserved estimates for the slope parameter $g_{1 \text {,new }}$ across different measurement conditions, which should help to increase confidence in predictions under future climates. The modifications to the model arguably represent a more mechanistic basis for stomatal responses to light, compared to the Medlyn model, although it is still very empirical and simplistic. Whereas more mechanistic models can typically be expected to do a better job in generating new insights and predicting $g_{\mathrm{s}}$ outside the validated range (Buckley 2017), they have a tendency to become too complex or include difficult to estimate parameters, which can make inclusion in levels of greater scales tricky. Therefore, there is still a need to refine empirical models such as presented here.

Although tobacco guard cells are known to respond only very weakly to the addition of blue light (Marten et al. 2008), it is possible that the slope parameters $g_{1}$ and $g_{1 \text {,new }}$ may not strictly represent only the quantitative stomatal 'red' light response for the second set of response curves. Further testing in different species will need to be done to verify this. Interestingly, the over-excitation of photosystem II compared to photosystem I by blue light may directly promote a more reduced $P Q$ redox state, which is hypothesized to lead to stomatal opening (Busch 2014; Głowacka et al. 2018). If so, the putative causal relationship between $1-q_{\mathrm{L}}$ and $g_{\mathrm{s}}$ implies that the stronger response of stomatal conductance to blue light may also arise via the 'red light' response, i.e. 

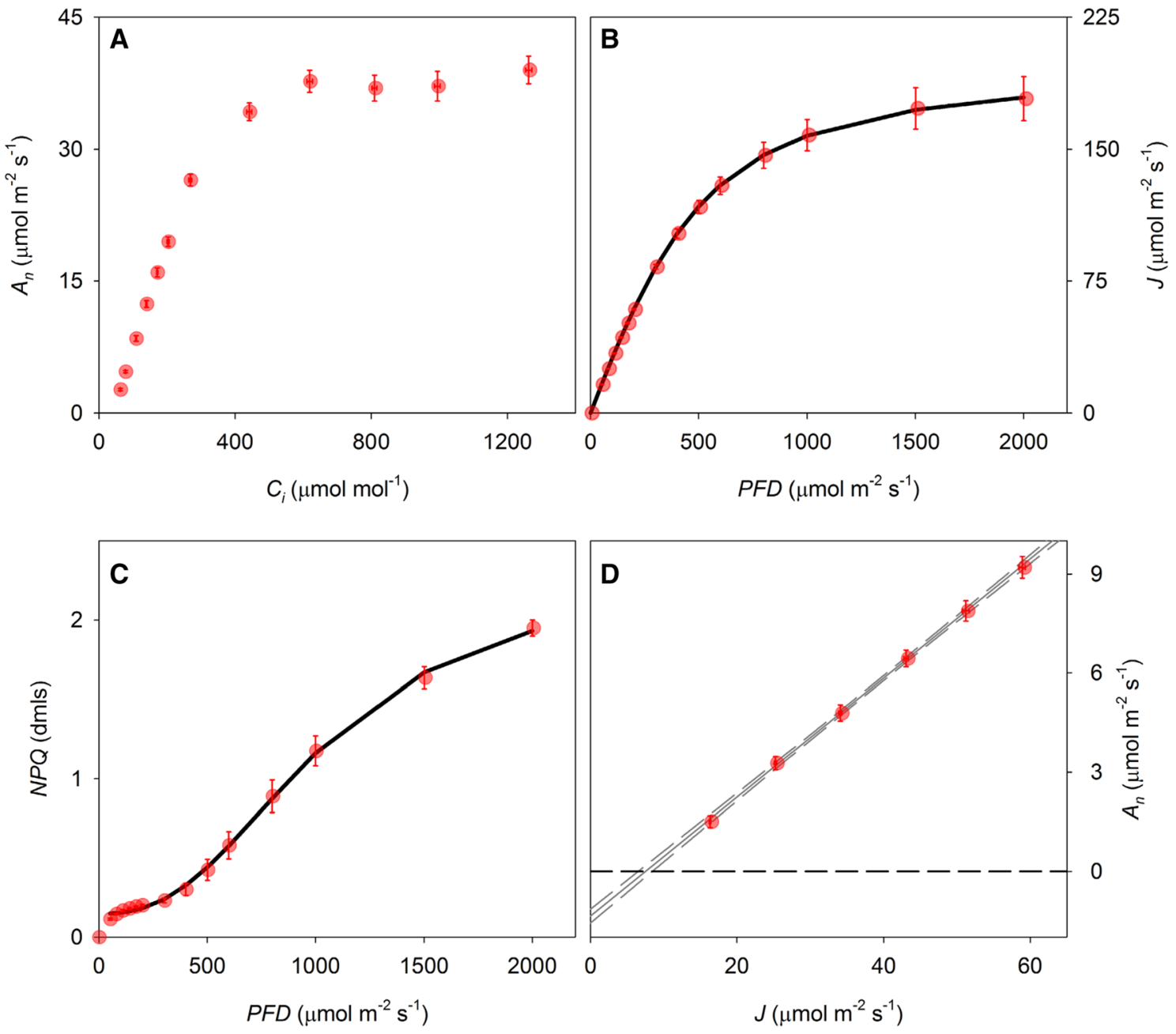

Fig. 4 Response curves to derive model parameters for the photosynthesis model. Net assimilation rate $A_{n}$ plotted as a function of a intercellular $\mathrm{CO}_{2}$ concentration $\left(C_{\mathrm{i}}\right)$, b whole-chain electron transport $(J)$ and $\mathbf{c}$ non-photochemical quenching (NPQ) plotted as a function of incident light (PFD) and $\mathbf{d} A_{n}$ plotted as a function of $J$. Solid lines in $\mathbf{b}$ and $\mathbf{c}$ depict model fits (Eqs. 4 and 6). The data in $\mathbf{d}$ were used

without the phototropin signalling cascade, although this effect would be more apparent at higher ratios between red and blue light than 9:1 used here and would also depend on parallel effects on induction of NPQ.

\section{Estimation of NPQ and $q_{\mathrm{L}}$}

To couple the new model of $g_{s}$ based on $1-q_{\mathrm{L}}$ with other models, requires accurate prediction of $q_{\mathrm{L}}$. We have presented a simple extension to the widely used FvCB model for photosynthesis (Farquhar et al. 1980), which is easy to parameterize and can be used to predict $q_{\mathrm{L}}$ reasonably well across a range of light intensities (Fig. 6). To circumvent the need for dark measurements for $F_{0}^{\prime}$, we simulated nonphotochemical quenching and photo-inactivation effects to estimate mitochondrial respiration rate not associated with photorespiration $\left(R_{\mathrm{d}}\right)$ as the $y$ intercept of the linear correlation. Solid and dashed lines in $\mathbf{d}$ show linear regressions and $95 \%$ confidence intervals, respectively. Error bars indicate standard errors $(n=6$ biological replicates)

on $F_{0}$. For non-photochemical quenching effects we used the formulation for $F_{0}^{\prime}$ by Oxborough and Baker (1997), which simulates the decrease in $F_{\mathrm{o}}^{\prime}$ based on the decrease in $F_{\mathrm{m}}^{\prime}$ relative to $F_{\mathrm{m}}$. The fluorescence increase due to photo-inactivation was simulated by an empirical relationship with the estimated energy flux through non-photochemical dissipation pathways (fluorescence, as well as regulated and constitutive thermal dissipation), which has been shown to be linearly correlated with the rate coefficient of photo-inactivation of PSII reaction centres (Hendrickson et al. 2005). This relationship was calibrated on the differences between $F_{\mathrm{oNPQ}}^{\prime}$ and measured $F_{\mathrm{o}}^{\prime}$ (by turning off actinic light and application of weak far-red illumination) under controlled conditions, which confirmed a 


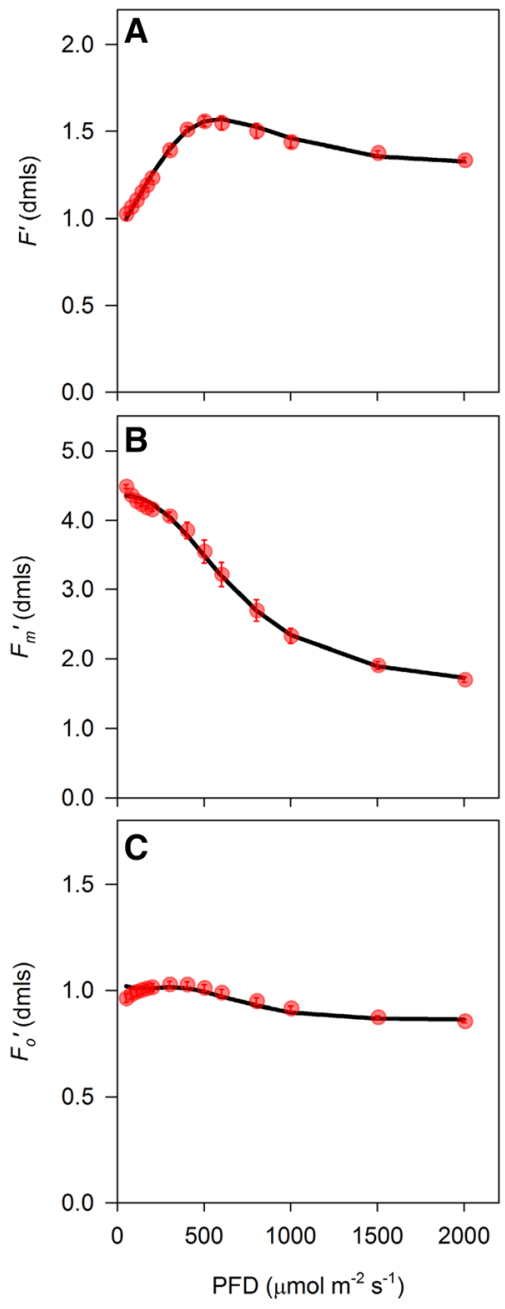

Fig. 5 a Steady state fluorescence $\left(F^{\prime}\right)$, b maximal fluorescence under illumination $\left(F_{\mathrm{m}}^{\prime}\right)$ and $\mathbf{c}$ minimal fluorescence under illumination $\left(F_{\mathrm{o}}^{\prime}\right)$. Symbols indicate measurements (scaled to corresponding $F_{m}$ measurement), solid lines show model simulations. Error bars indicate standard errors ( $n=6$ biological replicates)

strong linear relationship, except for very low PFD where the relationship tended to be slightly curvi-linear.

The model simulations of $q_{\mathrm{L}}$ further depend on accurate estimation of NPQ. We chose to use an empirical sigmoidal Hill function, which was sufficient to demonstrate the use of $1-q_{\mathrm{L}}$ as a predictor of light-induced stomatal movements, but carries limited biological meaning. Additionally, treatment of $N P Q$ as an independent parameter does not take account of the intimate connection between photosynthesis and thermal dissipation of absorbed light energy in the photosynthetic antenna complexes. The presented approach may therefore be improved by linking the description of NPQ by Eqs. $(6 a, 6 b)$ to the parameters describing photosynthetic capacity such as $V_{\mathrm{cmax}}$ and $J_{\max }$, or using altogether more mechanistic models for simulation of photosynthesis and non-photochemical quenching (e.g. Zaks et al. 2012; Morales et al. 2018). Interestingly, the estimation of NPQ at larger scales has gained a lot of interest recently due to development of gross primary productivity (GPP) proxies based on ground-based or remotely sensed measurements of solar induced fluorescence (SIF, reviewed by Porcar-Castell et al. (2014) and several others). Here, the interaction between steady state photosynthesis and the passive emission of chlorophyll fluorescence provides an optical signal which can be used to estimate GPP. However, since steady state fluorescence is the product of absorbed light and the quantum yield of fluorescence, both photochemical and non-photochemical quenching can affect the SIF signal. Hence, additional modelling or parallel proxies for NPQ are required in order to use SIF signals as a proxy for GPP. One oftenused proxy for NPQ is the photochemical reflectance index (PRI, Gamon et al. 1992), which is based on the broadband scattering change at $531 \mathrm{~nm}$ associated with pigment conversions in the xanthophyll cycle and a conformational change in the PSII antenna, which accompanies energydependent quenching (Bilger and Bjorkman 1994; Johnson et al. 2009). Short-term (diurnal) variations in the PRI signal can be successfully used to provide a proxy for canopy or ecosystem light use efficiency (Gamon et al. 1997; Hilker et al. 2011). Our demonstration that $1-q_{\mathrm{L}}$ can be used as a proxy for light-induced stomatal movements suggests that in addition to light use efficiency, optical proxies such as PRI may also turn out to be useful in constraining ecosystem water vapour exchange estimates based on stomatal conductance in terrestrial biosphere models.

\section{More robust estimation of $g_{s}$ across different conditions}

We have demonstrated that using the fluorescence parameter $1-q_{\mathrm{L}}$ instead of $A_{n}$ makes the slope parameter in the stomatal conductance model ( $g_{1}$ and $\left.g_{1 \text {,new }}\right)$ more robust against differing measurement conditions (Fig. 3). In addition, residuals of the modified stomatal conductance model were consistently lower than for the Medlyn model across a wide range of parameter values (Fig. S2). This is of great value to increase confidence in predictions of vegetation responses to future climate conditions. Slope and intercept parameters of BWB model (Ball et al. 1986) and the derivation by Medlyn et al. (2011) have been reported to vary substantially between species, and species-specific parameterization greatly improved model predictions of $A_{n}$ and $g_{\mathrm{s}}$ (Wolz et al. 2017). If the light response of stomatal opening is indeed mechanistically connected to the PQ redox state, the modified model may also provide a more generic parameterization across species, but more measurements on different species will be needed to assess this. However, although the species-specific differences between slope and 


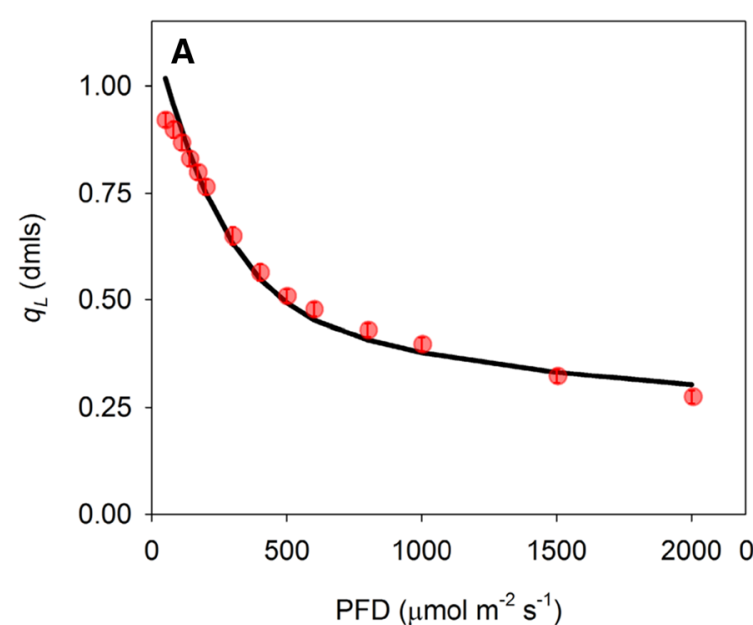

Fig. 6 a Fluorescence parameter $q_{\mathrm{L}}$ as a function of light intensity (PFD), symbols indicate measurements, solid line shows model simulations. b Correlation between observed and modelled $q_{\mathrm{L}}$ shown in panel a. Solid and dashed lines in $\mathbf{b}$ depict linear regression

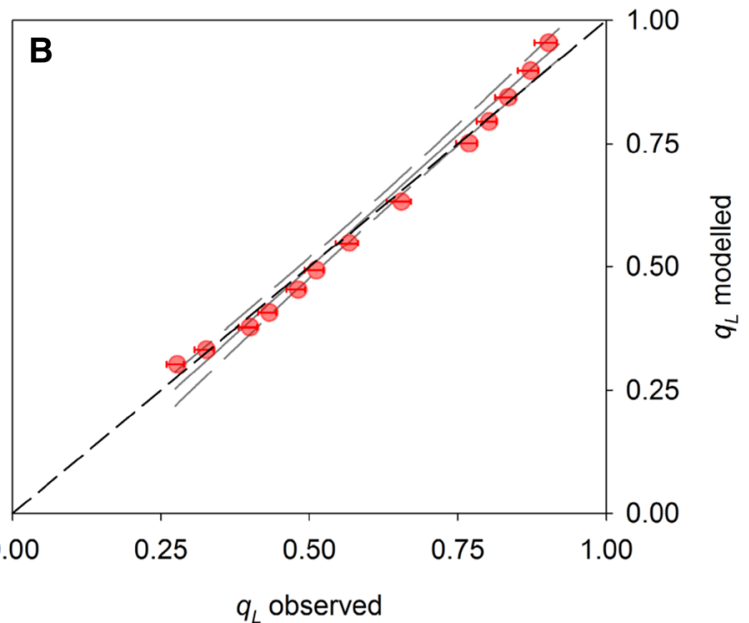

$(y=1.08 x-0.04)$ and $95 \%$ confidence intervals, respectively. Slope and intercept did not deviate significantly from $x=y$ shown by the black dashed line $(p>0.05)$. Error bars indicate standard errors $(n=6$ biological replicates)
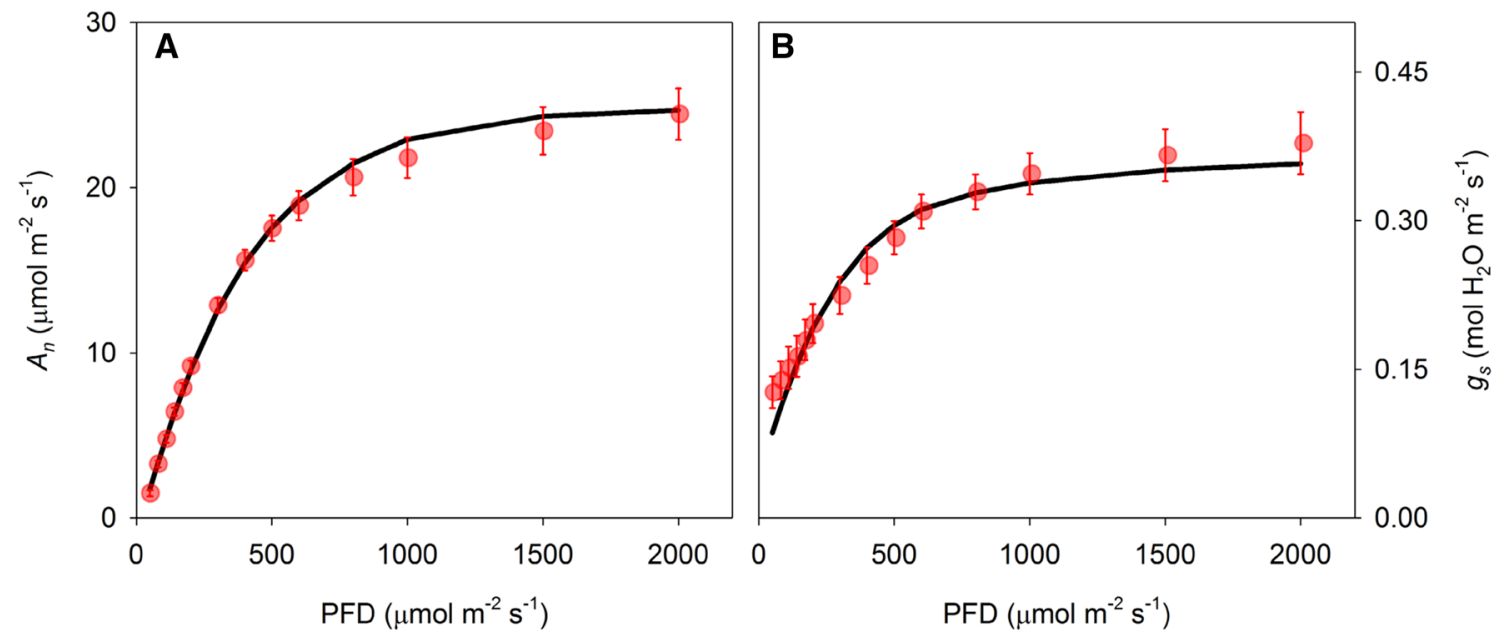

Fig. 7 Observed and modelled $A_{n}(\mathbf{a})$ and $g_{\mathrm{s}}(\mathbf{b})$ as a function of light intensity. Model simulations were performed with the coupled model for photosynthesis and stomatal conductance. Error bars indicate standard errors ( $n=6$ biological replicates)

intercept parameters as shown by Wolz et al. (2017) may have been aggravated by using $A_{n}$ as an estimator of the stomatal light response, it is very likely that considerable species-specific parameterization will remain necessary in the modified model. For instance, whereas the blue-light response of guard cells is relatively weak in tobacco, which allowed lumping it in with the quantitative response in a single slope parameter $g_{1, \text { new }}$, this may possibly require more explicit parameterization in species with a stronger response to blue light. The level of NPQ is also known to vary between species (Demmig-Adams 1998), within species (Jung and Niyogi 2009; Kasajima et al. 2011; Ortiz et al. 2017) and with leaf age and plant development stage (Bielczynski et al. 2017) and the same is true for photosynthetic capacity and leaf morphology. This is also evident from the model simulations of field-grown tobacco, where better fits could be obtained with substantially increased slope parameters $\left(g_{1}, g_{1, \text { new }}\right)$ and decreased intercepts $\left(g_{0}\right.$, $g_{0, \text { new }}$; Fig. 8 and Fig. S2). Different parameter values are to be expected based on known differences in stomatal 


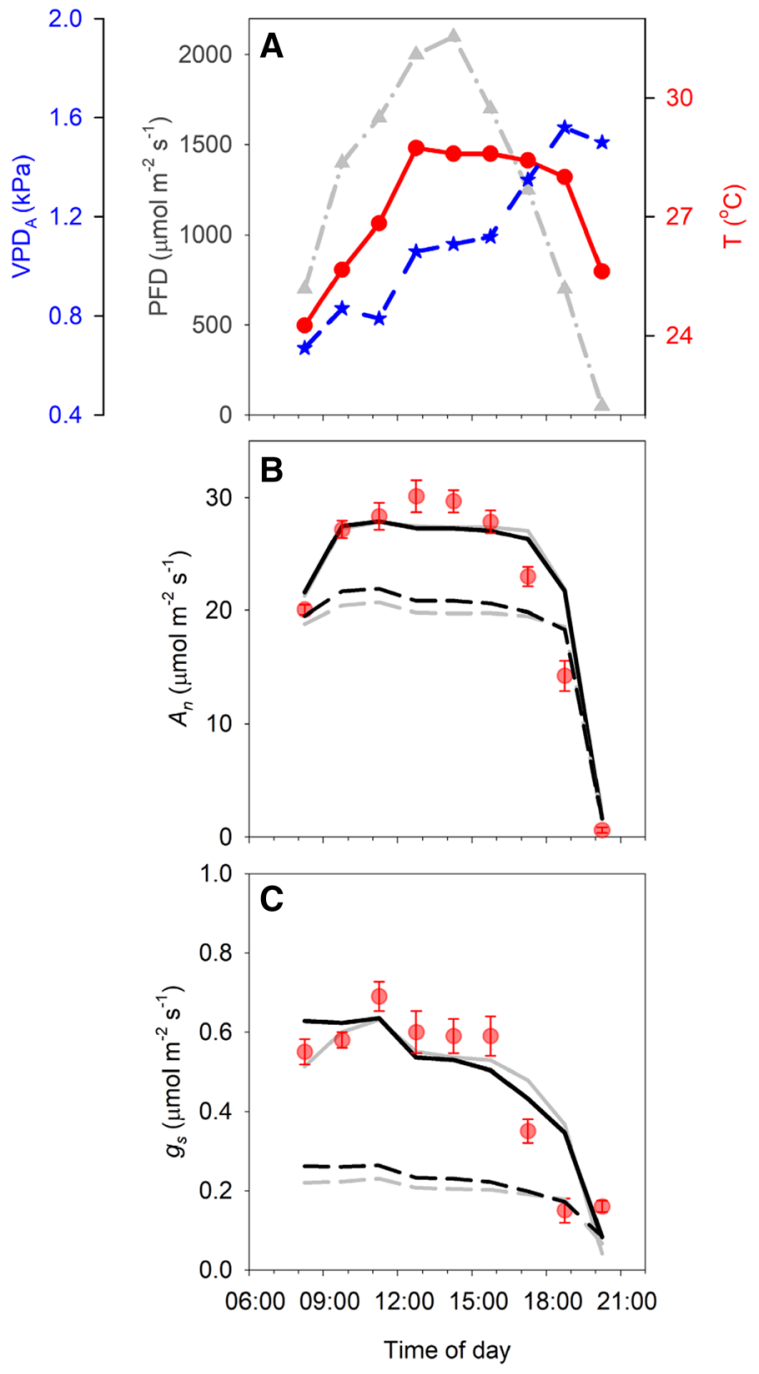

Fig. 8 a Diurnal measurements of light intensity (PFD), air temperature $(\mathrm{T})$ and air vapour pressure deficit $\left(\mathrm{VPD}_{\mathrm{A}}\right)$ during July 21,2015 in Urbana, Illinois, USA. b Observed (symbols) and modelled (lines) net assimilation rate $\left(A_{n}\right)$ at 90 min intervals. Simulations were performed with the coupled photosynthesis-stomatal conductance model, using the weather data in a as input. Lines show model predictions using either the Medlyn (grey lines) or the modified stomatal conductance model (black lines), with parameter estimates from controlled conditions (dotted lines) or re-calibrated on field-grown plants (solid lines) (c) Observed (symbols) and modelled (lines) stomatal conductance $\left(g_{\mathrm{s}}\right)$. Line legend as explained for $\mathbf{b}$. Error bars indicate standard errors $(n=7-8$ biological replicates)

acclimation between controlled and field conditions (Matthews et al. 2018). Late in the photoperiod, both models overestimated $A_{n}$ and $g_{s}$. This may require more detail in the simulation of stomatal responses to vapour pressure deficit, leaf water status or long-term diurnal stomatal movements. For example, inclusion of a diurnal sinusoidal pattern in the BWB stomatal conductance model greatly improved prediction accuracy (Matthews et al. 2018). The physiological basis for these diurnal stomatal movements is not entirely clear, but circadian regulation (Hassidim et al. 2017) and interactions with sugar and ethylene signals (Kelly et al. 2013; Haydon et al. 2017) are well-known to have an impact on stomatal conductance. It is also clear that $1-q_{\mathrm{L}}$ will be subject to much faster changes than stomatal responses which suggests that the slower stomatal responses may reflect a time-averaged redox signal initiated at the chloroplastic PQ pool. Interestingly, the use of $1-q_{\mathrm{L}}$ in the stomatal conductance model would also allow the kinetic behaviour of NPQ to impact stomatal dynamic properties, similar to our findings for steady state values (Głowacka et al. 2018). Namely, build-up of sustained NPQ throughout the photoperiod would directly dampen the signal for stomata to open in response to light. Further work is needed to test the relationship between PQ redox state and red light-induced stomatal movements. The presented model equations provide a structured framework to generate and verify hypotheses based on this putative relationship.

Acknowledgements We would like to thank David Drag and Ben Harbaugh for plant management in greenhouse and field studies, Liana Acevedo-Siaca for help with the diurnal gas exchange measurements and Nerea Ubierna and three anonymous reviewers for helpful comments on a previous version of the manuscript.

Funding This work was supported by the research project Realizing Increased Photosynthetic Efficiency (RIPE) that is funded by the Bill \& Melinda Gates Foundation, Foundation for Food and Agriculture Research, and the Department for International Development under Grant Number OPP1172157.

\section{Compliance with ethical standards}

Conflict of interest The authors declare that they have no conflict of interest.

Open Access This article is distributed under the terms of the Creative Commons Attribution 4.0 International License (http://creativeco mmons.org/licenses/by/4.0/), which permits unrestricted use, distribution, and reproduction in any medium, provided you give appropriate credit to the original author(s) and the source, provide a link to the Creative Commons license, and indicate if changes were made.

\section{Appendix}




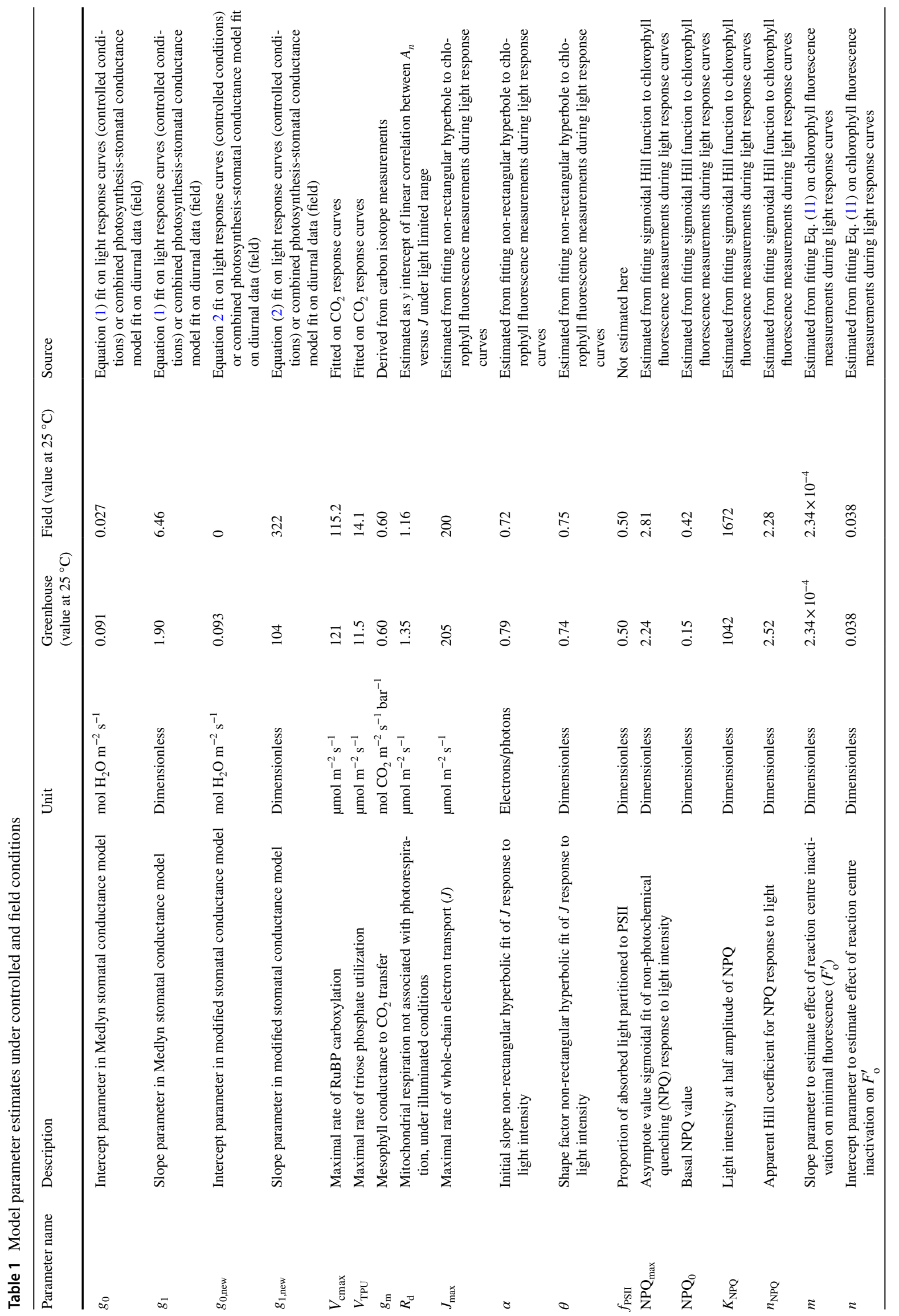




\section{References}

Assman SM, Shimazaki K (1999) The multisensory guard cell. stomatal responses to blue light and abscisic acid. Plant Physiol 119:809-815

Ball JT, Woodrow IE, Berry JAA, Model (1986) Predicting stomatal conductance and its contribution to the control of photosynthesis under different environmental conditions. In: Biggins J (ed) Progress in photosynthesis research. Springer, Providence, pp 221-224

Baroli I, Price GD, Badger MR, Von Caemmerer S (2008) The contribution of photosynthesis to the red light response of stomatal conductance. Plant Physiol 146:737-747

Bellasio C, Quirk J, Buckley TN, Beerling DJ (2017) A dynamic hydro-mechanical and biochemical model of stomatal conductance for C4 photosynthesis. Plant Physiol 175:104-119

Bielczynski LW, Lacki MK, Hoefnagels I, Gambin A, Croce R (2017) Leaf and plant age affect photosynthetic performance and photoprotective capacity. Plant Physiol 175:1634-1648

Bilger W, Bjorkman O (1994) Relationships among violaxanthin deepoxidation, thylakoid membrane conformation, and nonphotochemical chlorophyll fluorescnece quenching in leaves of cotton (Gossypium hirsutum L.). Planta 193:238-246

Bonan GB, Williams M, Fisher RA, Oleson KW (2014) Modeling stomatal conductance in the earth system: linking leaf water-use efficiency and water transport along the soil-plant-atmosphere continuum. Geosci Model Dev 7:2193-2222

Buckley TN (2017) Modeling stomatal conductance. Plant Physiol 174:572-582

Busch FA (2014) Opinion: the red-light response of stomatal movement is sensed by the redox state of the photosynthetic electron transport chain. Photosynth Res 119:131-140

Chater CCC, Caine RS, Fleming AJ, Gray JE (2017) Origins and evolution of stomatal development. Plant Physiol 174:624-638

Damour G, Simonneau T, Cochard H, Urban L (2010) An overview of models of stomatal conductance at the leaf level. Plant Cell Environ 33:1419-1438

Demmig-Adams B (1998) Survey of thermal energy dissipation and pigment composition in sun and shade leaves. Plant Cell Physiol 39:474-482

Dougherty RL, Bradford JA, Coyne PI, Sims PL (1994) Applying an empirical model of stomatal conductance to three $\mathrm{C} 4$ grasses. Agric For Meteorol 67:269-290

Engineer $\mathrm{CB}$ et al (2016) $\mathrm{CO}_{2}$ sensing and $\mathrm{CO}_{2}$ regulation of stomatal conductance: advances and open questions. Trends Plant Sci 21:16-30

Evans J, Von Caemmerer S (2013) Temperature response of carbon isotope discrimination and mesophyll conductance in tobacco. Plant Cell Environ 36:745-756

Farquhar GD, Von Caemmerer S, Berry JA (1980) A biochemical model of photosynthetic $\mathrm{CO}_{2}$ assimilation in leaves of $\mathrm{C} 3$ species. Planta 149:78-90

Gamon JA, Penuelas J, Field CB (1992) A narrow-waveband spectral index that tracks diurnal changes in phoyosynthetic efficiency. Remote Sens Environ 41:35-44

Gamon JA, Serrano L, Surfus JS (1997) The photochemical reflectance index: an optical indicator of photosynthetic radiation-use efficiency across species, functional types, and nutrient levels. Oecologia 112:492-501

Genty B, Briantais JM, Baker NR (1989) The relationship between the quantum yield of photosynthetic electron transport and photochemical quenching of chlorophyll fluorescence. Biochem Biophys Acta 990:87-92
Głowacka K et al (2018) Photosystem II Subunit S overexpression increases the efficiency of water use in a field-grown crop. Nat Commun 9:868

Gutschick VP, Simonneau T (2002) Modelling stomatal conductance of field-grown sunflower under varying soil water content and leaf environment: comparison of three models of stomatal response to leaf environment and coupling with an abscisic acid-based model of stomatal response to soil drying. Plant Cell Environ 25:1423-1434

Hassidim $M$ et al (2017) CIRCADIAN CLOCK ASSOCIATED1 (CCA1) and the circadian control of stomatal aperture. Plant Physiol 175:1864-1877

Haydon MJ, Mielczarek O, Frank A, Roman A, Webb AA (2017) Sucrose and ethylene signaling interact to modulate the circadian clock. Plant Physiol 175:947-958

Hendrickson L, Forster B, Pogson BJ, Chow WS (2005) A simple chlorophyll fluorescence parameter that correlates with the rate coefficient of photoinactivation of photosystem II. Photosynth Res 84:43-49

Hilker $\mathrm{T}$ et al (2011) Inferring terrestrial photosynthetic light use efficiency of temperate ecosystems from space. J Geophys Res 116:1-11

Inoue S, Kinoshita T (2017) Blue light regulation of stomatal opening and the plasma membrane $\mathrm{H}^{+}$-ATPase. Plant Physiol 174:531-538

Johnson MP, Perez-Bueno ML, Zia A, Horton P, Ruban AV (2009) The zeaxanthin-independent and zeaxanthin-dependent qE components of nonphotochemical quenching involve common conformational changes within the photosystem II antenna in Arabidopsis. Plant Physiol 149:1061-1075

Jung H-S, Niyogi KK (2009) Quantitative genetic analysis of thermal dissipation in Arabidopsis. Plant Physiol 150:977-986

Kaiser H, Kappen L (1997) In situ observations of stomatal movements in different light-dark regimes: the influence of endogenous rhythmicity and long-term adjustments. J Exp Bot 48:1583-1589

Kasajima I, Ebana K, Yamamoto T, Takahara K, Yano M, KawaiYamada M, Uchimiya H (2011) Molecular distinction in genetic regulation of nonphotochemical quenching in rice. Proc Natl Acad Sci USA 108:13835-13840

Kelly G et al (2013) Hexokinase mediates stomatal closure. Plant J 75:977-988

Kollist H, Nuhkat M, Roelfsema MRG (2014) Closing gaps: linking elements that control stomatal movement. New Phytol 203:44-62

Kramer DM, Johnson G, Kiirats O, Edwards GE (2004) New fluorescence parameters for the determination of QA redox state and excitation energy fluxes. Photosynth Res 79:209-218

Kromdijk J, Schepers H, Griffiths H (2010) Can the progressive increase of $\mathrm{C} 4$ bundle sheath leakiness at low PFD be explained by incomplete suppression of photorespiration? Plant Cell Environ 33:1935-1948

Lawson T, Lefebvre S, Baker NR, Morison JI, Raines CA (2008) Reductions in mesophyll and guard cell photosynthesis impact on the control of stomatal responses to light and $\mathrm{CO}_{2}$. J Exp Bot 59:3609-3619

Lawson T, Simkin AJ, Kelly G, Granot D (2014) Mesophyll photosynthesis and guard cell metabolism impacts on stomatal behaviour. New Phytol 203:1064-1081

Leuning R (1995) A critical appraisal of a combined stomatal-photosynthesis model for C3 plants. Plant Cell Environ 18:339-355

Liang YK, Dubos C, Dodd IC, Holroyd GH, Hetherington AM, Campbell MM (2005) AtMYB61, an R2R3-MYB transcription factor controlling stomatal aperture in Arabidopsis thaliana. Curr Biol 15:1201-1206

Loriaux SD, Avenson TJ, Welles JM, McDermitt DK, Eckles RD, Riensche B, Genty B (2013) Closing in on maximum yield of 
chlorophyll fluorescence using a single multiphase flash of subsaturating intensity. Plant Cell Environ 36:1755-1770

Marten H, Hyun T, Gomi K, Seo S, Hedrich R, Roelfsema MRG (2008) Silencing of NtMPK4 impairs $\mathrm{CO}_{2}$-induced stomatal closure, activation of anion channels and cytosolic $\mathrm{Ca}^{2+}$ signals in Nicotiana tabacum guard cells. Plant J 55:698-708

Matthews JSA, Vialet-Chabrand SRM, Lawson T (2018) Acclimation to fluctuating light impacts the rapidity of response and diurnal rhythm of stomatal conductance. Plant Physiol 176:1939-1951

Medlyn B et al (2011) Reconciling the optimal and empirical approaches to modelling stomatal conductance. Glob Chang Biol 17:2134-2144

Messinger SM, Buckley TN, Mott KA (2006) Evidence for involvement of photosynthetic processes in the stomatal response to $\mathrm{CO}_{2}$. Plant Physiol 140:771-778

Mielke MS, Oliva MA, De Barros NF, Penchel RM, Martinez CA, De Almeida AC (1999) Stomatal control of transpiration in the canopy of a clonal Eucalyptus grandis plantation. Trees 13:152-160

Morales A, Yin X-Y, Harbinson J, Driever SM, Kramer DM, Struik PC (2018) In silico analysis of the regulation of the photosynthetic electron transport chain in $\mathrm{C} 3$ plants. Plant Physiol 176:1247-1261

Mott KA, Parkhurst DF (1991) Stomatal responses to humidity in air and helox. Plant Cell Environ 14:509-515

Mott KA, Sibbernsen ED, Shope JC (2008) The role of the mesophyll in stomatal responses to light and $\mathrm{CO}_{2}$. Plant Cell Environ 31:1299-1306

Ortiz D, Hu J, Fernandez MGS (2017) Genetic architecture of photosynthesis in Sorghum bicolor under non-stress and cold stress conditions. J Exp Bot 68:4545-4557

Oxborough K, Baker NR (1997) Resolving chlorophyll a fluorescence images of photosynthetic efficiency into photochemical and nonphotochemical components - calculation of $\mathrm{qP}$ and $\mathrm{Fv}^{\prime} / \mathrm{Fm}^{\prime}$ without measuring Fo". Photosynth Res 54:135-142

Pearcy RW, Schulze E-D, Zimmermann R (1989) Measurement of transpiration and leaf conductance. In: Pearcy RW, Ehleringer JR, Mooney HA, Rundel PW (eds) Plant physiological ecologyfield methods and instrumentation. Chapman and Hall, London, pp 137-153

Porcar-Castell A et al (2014) Linking chlorophyll a fluorescence to photosynthesis for remote sensing applications: mechanisms and challenges. J Exp Bot 65:4065-4095

Sharkey TD, Bernacchi CJ, Farquhar GD, Singsaas EL (2007) Fitting photosynthetic carbon dioxide response curves for $\mathrm{C} 3$ leaves. Plant Cell Environ 30:1035-1040
Tenhunen JD, Sala A, Harley PC, Dougherty RL, Reynolds JF (1990) Factors influencing carbon fixation and water use by Mediterranean sclerophyll shrubs during summer drought. Oecologia 82:381-393

Vialet-Chabrand SRM, Matthews JSA, McAusland L, Blatt MR, Griffiths H, Lawson T (2017) Temporal dynamics of stomatal behavior: modelling and implications for photosynthesis and water use. Plant Physiol 174:603-613

Von Caemmerer S, Lawson T, Oxborough K, Baker NR, Andrews TJ, Raines CA (2004) Stomatal conductance does not correlate with photosynthetic capacity in transgenic tobacco with reduced amounts of Rubisco. J Exp Bot 55(400):1157-1166

Wang YP, Leuning R (1998) A two-leaf model for canopy conductance, photosynthesis and partitioning of available energy I. Model description and comparison with a multi-layered model. Agric For Meteorol 91:89-111

Wang F-F, Lian H-L, Kang C-Y, Yang H-Q (2010) Phytochrome B is involved in mediating red light-induced stomatal opening in Arabidopsis thaliana. Mol Plant 3:246-259

Wang Y et al (2017) Unexpected connections between humidity and ion transport discovered using a model to bridge guard cell-to-leaf scales. Plant Cell 29:2921-2939

Wehr R et al (2017) Dynamics of canopy stomatal conductance, transpiration, and evaporation in a temperature deciduous forest, validated by carbonyl sulfide uptake. Biogeosciences 14:389-401

Wei Z, Yoshimura K, Wang L, Miralles DG, Jasecko S, Lee X (2017) Revisiting the contribution of transpiration to global terrestrial evapotranspiration. Geophys Res Lett 44:2792-2801

Whitehead D (1998) Regulation of stomatal conductance and transpiration in forest canopies. Tree Physiol 18:633-644

Wolz KJ, Wertin TM, Abordo M, Wang D, Leakey A (2017) Diversity in stomatal function is integral to modelling plant carbon and water fluxes. Nat Ecol Evol 1:1292-1298

Yin X-Y, Struik PC, Romero P, Harbinson J, Evers JB, Van der Putten PEL, Vos J (2009) Using combined measurements of gas exchange and chlorophyll fluorescence to estimate parameters of a biochemical $\mathrm{C} 3$ photosynthesis model: a critical appraisal and a new integrated approach applied to leaves in a wheat (Triticum aestivum) canopy. Plant Cell Environ 32:448-464

Zaks J, Amarnath K, Kramer DM, Niyogi KK, Fleming GR (2012) A kinetic model of rapidly reversibly nonphotochemical quenching. Proc Natl Acad Sci USA 109:15757-15762

Publisher's Note Springer Nature remains neutral with regard to jurisdictional claims in published maps and institutional affiliations. 